\title{
Fever of Unknown Origin - A Child With an Unusual Case of Juvenile Idiopathic Arthritis
}

\author{
Purnima Gyawali', Deepika Gyawali', Sharda Acharya
}

${ }^{1}$ KIST Medical College and Teaching Hospital, Lalitpur, Nepal

${ }^{2}$ Chirayu National Hospital \& Medical Institute, Kathmandu, Nepal

${ }^{3}$ Department of Pediatrics, KIST Medical College and Teaching Hospital, Lalitpur, Nepal

\section{ABSTRACT}

Fever of unknown origin in the pediatric population is fever $>38.3^{\circ} \mathrm{C}\left(101^{\circ} \mathrm{F}\right)$ of at least seven days' duration, in which no diagnosis is apparent after initial outpatient or hospital evaluation that includes a careful history and physical examination and initial laboratory assessment. Fever of unknown origin is a diagnostic challenge, with a broad spectrum of causes classified as infectious, malignant/neoplastic, rheumatic/inflammatory, and miscellaneous disorders. A high index of suspicion should be kept for juvenile idiopathic arthritis in children presenting with unexplained fever and joint symptoms and should be appropriately managed. The case described here is of a 13-year-old female from Nepal, who presented to the Pediatric outpatient department of KISTMCTH with a history of fever and arthralgia for three months.

Keywords: Infection; Joint pain; Juvenile Inflammatory arthritis

\section{Correspondence:}

Dr. Purnima Gyawali, MBBS

KIST Medical College and Teaching Hospital, Lalitpur, Nepal

ORCID ID: 0000-0003-3738-2260

Email: gpurnima05@gmail.com

Submitted: $10^{\text {th }}$ June 2021

Accepted: $28^{\text {th }}$ June 2021

Source of Support: None

Conflict of Interest: No

Citation: Gyawali P, Gyawali D, Acharya S. Fever of Unknown Origin - A Child With an Unusual Case of Juvenile Rheumatoid Arthritis. NMJ 2021;4(1):459-61. DOI: $10.3126 / \mathrm{nmj} . \mathrm{v} 4 \mathrm{i} 1.38161$

\section{INTRODUCTION}

Pyrexia is one of the common symptoms, for which patients visit the pediatric Out Patient Department of any medical facility. Proper history taking, examination, and relevant investigations help in the diagnosis and management of the majority of children with fever. But still, there are times when fever becomes a diagnostic challenge. In a small subset of the population, the fever is persistent and remains unexplained despite thorough clinical evaluation and investigations. Fever of unknown origin (FUO)in the pediatric population is fever $>38.3^{\circ} \mathrm{C}\left(101^{\circ} \mathrm{F}\right)$ of at least seven days' duration, in which no diagnosis is apparent after initial outpatient or hospital evaluation that includes a careful history and physical examination and initial laboratory assessment. ${ }^{1}$ Etiology of FUO is broad and includes infectious, autoimmune, oncologic, neurologic, genetic, factitious, and iatrogenic causes. ${ }^{2}$ Here we present a case of a 13-year-old female child who presented to the Pediatric outpatient department of KISTMCTH with a history of fever and arthralgia for three months.

\section{\# CASE REPORT}

A 13-year-old female child was brought to the outpatient clinic with complaints of fever and arthralgia for three months. Fever was persistent type, with 1-2 spikes/week, measuring up to $105^{\circ}$ $\mathrm{F}$, and relieved by antipyretics. Fever spikes continued to increase in frequency and occurred daily for the last 10 days Her joint pain involved bilateral wrist, elbow, knees, and ankles. However, there 
was no redness or swelling, or limitation of movements in the affected joints. There was also a history of ecchymotic patches on her body, once in a month which resolved spontaneously. She had a history of $5 \mathrm{~kg}$ weight loss in the last 3 months. She also gave a history of recurrent sore throat, 5- 6 episodes in the past year. There was no history of contact with any patient with Tuberculosis. There was a history of recent travel to the malariaendemic region.

At the time of presentation, she was febrile, pulse rate was $88 / \mathrm{bpm}$ equally palpable pulses in all 4 limbs; respiratory rate, 20/min; arterial blood pressure, $100 / 80 \mathrm{mmHg}$. On physical examination, pallor was present, there was also a palpable posterior cervical lymph node size 2 X $2 \mathrm{~cm}$. On examination of the joints they was no redness, swelling or tender. There was no rash. Her oral cavity and cardiovascular, respiratory, abdominal, and nervous system examinations were normal.

Biochemical parameters of the patient included: white blood cell count (WBC), $12 \times 10^{3} / \mathrm{uL}$; hemoglobin $(\mathrm{Hb}), 11.7 \mathrm{gm} / \mathrm{dL}$; platelets, $285 \times 103 / \mathrm{uL}$; aspartate transaminase, $15 \mathrm{U} / \mathrm{L}$; alanine transaminase, $23 \mathrm{U} / \mathrm{L}$; erythrocyte sedimentation rate (ESR), $40 \mathrm{~mm} / \mathrm{h}$; C-reactive protein (CRP), $78.74 \mathrm{mg} / \mathrm{dL}(<0.5)$; procalcitonin, $<0.1 \mathrm{ng} / \mathrm{ml}$, and prothrombin time, $14 \mathrm{~s}(11-14)$. Peripheral blood smear showed microcytic hypochromic with mild anisocytosis, no other abnormal cell or hemoparasite were seen. Malarial parasites were not detected in peripheral blood smears. Her Mantoux test was positive with $16 \mathrm{~mm}$ of induration. Sputum for Acid Fast Bacilli and GeneXpert for MTb were negative. Chest X-ray PA view was normal. ASO latex test was done which was positive. Rheumatoid factor (RF), anti-CCP, antinuclear antibody, and anti-ds-DNA antibody were negative. Complement C3 was $170.4 \mathrm{mg} / \mathrm{dl}(90-180 \mathrm{mg} / \mathrm{dl})$ and C4 was $24.3 \mathrm{mg} / \mathrm{dl}(10-40 \mathrm{mg} / \mathrm{dl})$. Urinalysis was done and was within the normal limit. Bone marrow aspiration was performed to rule out hematological malignancies and infective causes. The bone marrow findings were unremarkable. No pathogenic agent was detected in urine, bone marrow, or blood cultures. Serological tests performed for Brucella antigen, scrub typhus, leptospirosis, dengue, kala-azar, hepatitis B virus, Hepatitis C virus, and human immunodeficiency virus (HIV) were negative. Echocardiography and abdominal ultrasonography were normal.RT-PCR for COVID-19 was negative.

Considering infection as one of the most common cause of FUO, Ceftriaxone and paracetamol was prescribed and was stopped after the culture reports came negative. Though tests for malaria were negative and there was no splenomegaly, empirically one course of chloroquine was prescribed. Despite the treatment, she continued to have multiple episodes of fever with chills which were associated with joint pain.

Following all tests, diagnosis of systemic-onset juvenile idiopathic arthritis (JIA) was made based on consideration of available anamnesis and clinical and laboratory findings. She was started on oral naproxen following which she was symptomatically better and discharged from the hospital on the $10^{\text {th }}$ day of admission. On subsequent follow-up visits, she was afebrile and her joint pain had subsided.

\section{DISCUSSION}

Causes of fever of unknown origin, can be classified as infectious, malignant/ neoplastic, rheumatic/inflammatory, and miscellaneous disorders. Study done by Chow et al in several developing countries showed infection the most common cause compared to other cause such as malignancy $(2 \%-12 \%)$, collagenvascular $(2 \%-21 \%)$, miscellaneous noninfectious $(2 \%-50 \%)$, and unknown $(12 \%-29 \%)^{2,3}$

Since the child had a history of weight loss, low-grade fever for months, TB was one of the differential diagnoses. Positive Mantoux test and high ESR further strengthened the possibility of TB. Sputum for Acid Fast Bacilli by Zeihl Neelsen stain and GeneXpert for MTb were negative.

Malaria is another possible cause of FUO in an endemic zone. Malaria cases are being reported from 65 of the 77 districts of Nepal. A population of approximately 22.8 million (83\% of Nepal's population) lives in these malaria-endemic districts. Amongst them, 2.03 million live in high-risk areas. ${ }^{4}$ Our patient had a positive history of travel to an endemic region and that raised the suspicion of disease. However, malaria parasite was not detected on the peripheral blood smear, and also the patient had cervical lymphadenopathy and rash which could not be explained by malaria alone.

In the context of Nepal, other tropical diseases to be considered are leptospirosis, Dengue, Brucellosis, Scrub typhus, and Kalazar. As personal hygiene is poor in context to our community hepatotropic viral diseases were also kept as the differential diagnosis. $^{5}$ However, serological tests for all the abovementioned diseases were negative. Similarly, bacterial infection was also ruled out as there was negative blood, bone marrow, and urine culture. Malignancy is one of the possible causes of FUO in children. ${ }^{4}$ However, bone marrow examination was negative for malignancy and other systemic examination including highresolution computed tomography didn't reveal any suspicion towards malignancy.

Another possible cause of FUO could be infective endocarditis which is commonly observed in pediatric patients. ${ }^{4}$ However, on auscultation, no murmur was identified which was confirmed by echocardiography. The echocardiography did not reveal any vegetation or any other abnormality. History of recurrent sore throat, fever, arthralgia, positive ASO titer, high ESR, made acute rheumatic fever a potential diagnosis. As there the echochardiography was normal, and there was no history of Sydenham chorea and migratory polyarthritis, erythema marginatum, and subcutaneous nodule, acute rheumatic fever was also excluded.

Since several common diseases that might be the cause of FUO were excluded, less common condition like Kawasaki disease was another differential diagnosis. Kawasaki disease is a selflimiting disease that predominantly involves small and mediumsized vessels. It is more common among children 5 years of age. ${ }^{6}$ However, Kawasaki disease has been diagnosed in children $>10$ years of age. ${ }^{7}$ Since our patient had prolonged fever, cervical lymphadenopathy, rashes, and elevated ESR, Kawasaki disease was considered. On examination, the patient didn't reveal conjunctivitis, mucosal changes (red, cracked lips, glossitis with strawberry tongue, or diffuse erythema of oral mucosa or oropharynx). Furthermore, the patient had ecchymotic rashes, not the maculopapular rashes typical for Kawasaki disease. ${ }^{6}$

Juvenile idiopathic arthritis is a diagnosis of exclusion. As the patient had joint pain involving the small symmetrical joints 
( wrist, elbow, ankle) and knee joints, JIA was considered. Juvenile idiopathic arthritis, the most common rheumatic disease in childhood, is characterized by persistent arthritis with no identifiable cause that begins before 16 years of age and is present for at least 6 weeks after exclusion of other diseases. ${ }^{8}$ Incidence of systemic JIA varies from country to country with an average incidence and prevalence rates detected range between 0.92 to $2.5 / 100.000$ and 1.2 to $11.3 / 100.000$, respectively. ${ }^{9}$

Systemic juvenile arthritis affects both females and males with the same frequency and may occur at any time during childhood. The presence of arthritis and intermittent fever for at least 2 weeks plus one of the following defines the disease: typical rash, generalized lymphadenopathy, hepatosplenomegaly, or serositis. ${ }^{10}$ Unlike other variants in Systemic onset JIA, auto-antibodies, ANAs, and rheumatoid factors are negative. ${ }^{10}$ Our patient had a negative Rheumatoid factor, anti-CCP, antinuclear antibody, and anti-ds-DNA antibody. Complement $\mathrm{C} 3$ and $\mathrm{C} 4$ were within the normal limit.

The management of JIA is aimed towards controlling active symptoms, achieving remission, and preventing joint damage.
Since the introduction of biological agents such as Methotrexate major advances has been achieved however, non-steroidal antiinflammatory drugs (NSAIDs) are the mainstay of treatment. ${ }^{11}$

Our patient was also symptomatically better after prescribing her with Naproxen. Thus, Juvenile rheumatoid arthritis was established as our diagnosis after excluding other causes of FUO and her positive response to NSAIDs.

\section{CONCLUSIONS}

Establishing an etiology of FUO in children may be challenging. The diagnosis of juvenile idiopathic arthritis is made after the exclusion of other diseases. A high index of suspicion should be kept for juvenile idiopathic arthritis in children presenting with unexplained fever and joint symptoms and should be appropriately managed.

\section{REFERENCES}

1. Landge AA, Singhal T. Etiology of Fever of Unknown Origin in Children from Mumbai, India. Indian Pediatr. 2018;55(1):71-2. Website

2. Antoon JW, Potisek NM, Lohr JA. Pediatric fever of unknown origin. Pediatr Rev. 2015;36(9):380-91. Crossref

3. KC Shiva R, KC Geetika, Gyawali P, Singh M, Sijapati MJ. Leprosy - Eliminated and forgotten: A case report. J Med Case Rep. 2019;13(1):1-7. Crossref

4. WHO. Nepal Malaria Programme Review. 2010;10-1. (Cited on $1^{\text {st }}$ June 2021) Available from: Website

5. EDCD. Infectious Disease Control Guideline. Epidemiol Dis Control Div [Internet]. 2016;12-8. (Cited on $1^{\text {st }}$ June 2021) Available from: Website

6. Patel RM, Shulman ST. Kawasaki disease: A comprehensive review of treatment options. J Clin Pharm Ther. 2015;40(6):620-5. Crossref
7. Jindal AK, Pilania RK, Guleria S, Vignesh P, Suri D, Gupta A, et al. Kawasaki Disease in Children Older Than 10 Years: A Clinical Experience From Northwest India. Front Pediatr. 2020;8:1-6. $\underline{\text { Crossref }}$

8. Paudyal BP, Gyawalee ME. Clinical profile of patients with juvenile idiopathic arthritis. J Patan Acad Heal Sci. 2016;3(1):10-4. Website

9. Hardal C, Erguven M, Saglam ZA. Systemic juvenile idiopathic arthritis as a fever of unknown origin. North Clin Istanb. 2017;4(1):81-4. Crossref

10. Barut K, Adrovic A, Şahin S, Kasapçopur Ö. Juvenile idiopathic arthritis. Balkan Med J. 2017;34(2):90-101. Crossref

11. Hussein Z, Wagdy R, Shawki M, Zohni S, Shehawy I. The pattern of juvenile idiopathic arthritis; a retrospective Egyptian study. Egypt J Pediatr Allergy Immunol. 2018;16(1):7-14. Crossref 